www.jmscr.igmpublication.org

Impact Factor 5.84

Index Copernicus Value: 83.27

ISSN (e)-2347-176x ISSN (p) 2455-0450

crossref DOI: _https://dx.doi.org/10.18535/jmscr/v5i5.167

\title{
A Rare Case of Solitary Plexiform Neurofibroma of Tongue: A Case Report and Review of Literature
}

\author{
Authors \\ Dr R. Keerthi ${ }^{1}$, Dr Rudra Paul Nandan ${ }^{2}$ \\ ${ }^{1}$ Professor, Department of Oral \& Maxillofacial Surgery, V.S Dental College and Hospital, Bangalore, \\ Karnataka, India \\ ${ }^{2}$ Post Graduate, Department of Oral \& Maxillofacial Surgery, V.S Dental College and Hospital, Bangalore, \\ Karnataka, India \\ Email: drnandan.rudrapaul@gmail.com,Ph.0-8971789795 \\ Corresponding Author \\ Dr Keerthi .R \\ Email:29.keerthi@gmail.com,Ph.0-9845216190
}

\begin{abstract}
The neurofibroma occurs as an isolated or multiple lesions frequently associated with neurofibromatosis type $1(\mathrm{NF} 1)^{3}$. A case of a sixty year old female with a solitary growth on the dorsum of tongue treated by total excision, diagnosed with plexiform neurofibroma based on immunohistochemistry marker S-100 is presented. She was having no other signs of any such lesions elsewhere in the body. Despite their occurrence in the head and neck region, this is a very rare finding in the oral cavity and one among $4-7 \%$ of patients reported to be affected by neurofibromatosis displaying oral manifestations. Plexiform neurofibroma is said to be indicative of Von Recklinghausen's disease (VRD) even though it may be the only manifestation of the disease ${ }^{2}$. Ideally surgical resection should be the treatment of choice and the diagnosis has to be confirmed by both histological and immunohistochemistry examination with S-100 tumour marker. Affected patients need thorough clinical examination and regular follow up to detect any recurrence, any malignant degeneration, or any manifestations of Von Recklinghausen's disease.
\end{abstract}

Key Words: Plexiform Neurofibroma, Von Recklinghausen's disease, Schwannoma, Neurofibroma.

\section{Introduction}

There are two types of nerve sheath tumors originating from the peripheral nerves: Schwannoma (neurilemmoma) and neurofibroma. Neurofibromas are a hallmark of neurofibromatosis, also known as Von Recklinghausens Disease (VRD). The difference between a neurofibroma and schwannoma is histological and it is important to differentiate between them because the former has more potential for malignant transformation ${ }^{2,8,9}$. In this paper one case of solitary plexiformneurofibroma of tongue is reported because of the rarity of its occurrence without any other pathology elsewhere.

\section{Materials and Methods}

\section{Case Report}

A sixty year old female presented to the Department of Oral \& maxillofacial Surgery, V.S Dental College \& Hospital, with a history of a 
solitary, small, slow growing, painless mass over her tongue which was present since one year with sudden onset, disturbing her phonation and mastication. There was no history of bleeding. Intra oral examination revealed a pale-pinkish, pedunculated growth with an irregular surface over the dorsum of right half of anterior two third of the tongue.

The growth measured $1 \mathrm{~cm} \times 1 \mathrm{~cm} \times 1 \mathrm{~cm}$ in length, breadth and height. The growth was firm, non -tender, non-reducible and non-pulsatile on palpation. No evidence of any other lesion or pathology elsewhere in the oral cavity or extraorally was found. On full body inspection also no other pathology was detected. Routine laboratory tests were within normal limits. The patient underwent surgical excision of the mass under local anesthesia with all the surgical protocols followed. The depth of infiltration of the mass was noticed to be restricted to being superior to the longitudinal muscles of the tongue but poor cleavage plane was present between the lesion and the muscles. The mass was excised in toto and primary closure of the surgical site was done with 4-0 vicryl suture material. Neither any nerve trunk nor any vascular structure was encountered on the surgical site. Bleeding was also very minimal than expected. The excised mass was sent for histopathological examination.

\section{Result}

Histopathological examination with $\mathrm{H} \& \mathrm{E}$ staining showed well circumscribed, un-encapsulated mass with hyperplastic parakertainized stratified squamous surface epithelium comprising spindle shaped cells with wavy nuclei admixed with small nerve fibres arranged in diffused pattern along with plexiform arrangement. Myxoid change within a nodule was seen. Mast cells were frequent. Mitotic activity was rare. Moderately dense fibrous tissue interspersed with plump fibroblasts were seen. Microscopic examination within toluidine blue stained section showed abundant mast cells. On immunohistochemical studies with marker S100 showed positive intense expression of tumour cells. The diagnosis was of plexiform neurofibroma.

Retrospectively the patient was examined for any other manifestations of VRD but no other lesions were found. The patient was on regular follow up for 6 months without any signs of recurrence.

Figures:

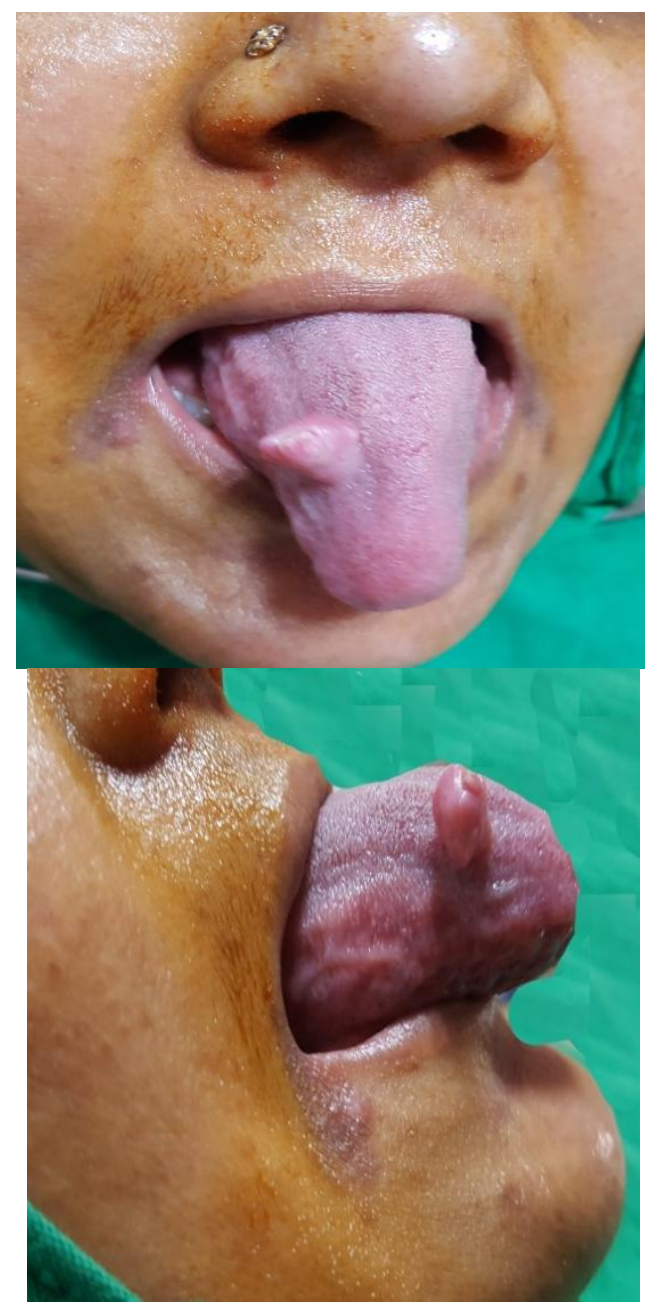

Fig.1 : Intra oral presentation of the growth on the dorsum of tongue.

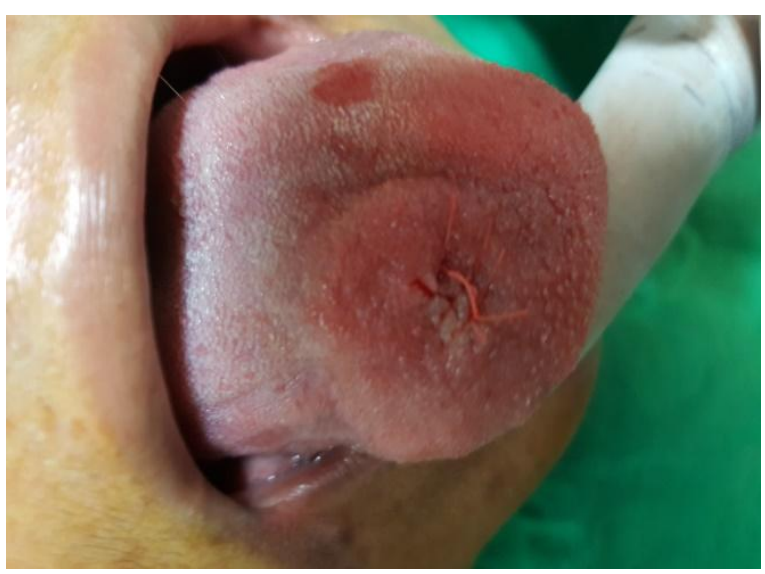

Fig 2: Primary closure after surgical excision 


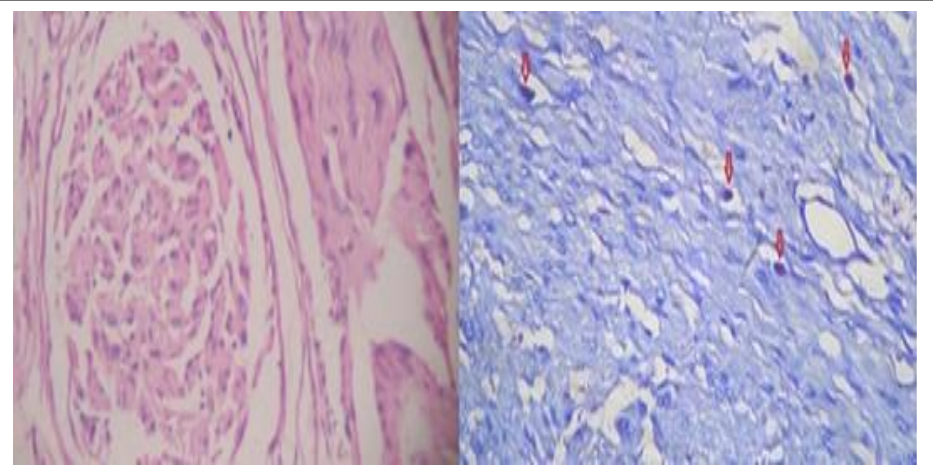

Fig.3 : High power view showing Schwann cells with elongated to round nuclei predominantly seen with crosses sectioned fascicles (H\&E, 400X), Mast cells with pink granules in the cytoplasm (arrows). (Toluidine blue, 100X)

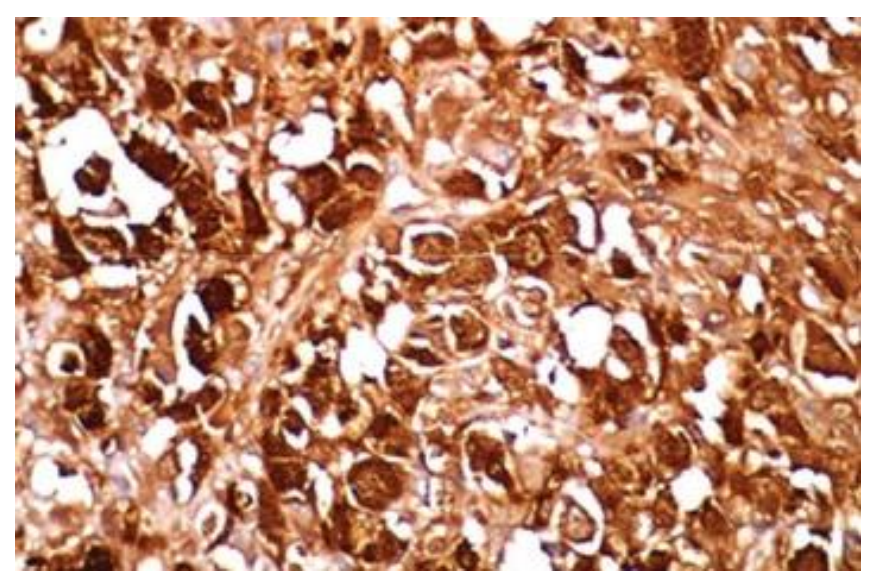

Fig.4: Immunohistochemical staining showing Positivity of tumor cells with S-100

\section{Discussion}

Neurofibromatosis type 1 (NF 1), is the most common form of neurofibromatosis and accounts for about $90 \%$ of all cases with a prevalence of 1 in 3000 persons world wide ${ }^{2}$. The condition may be inherited as an autosomal dominant trait or in rare case represents a sporadic localised mutation of the NF 1 tumor suppressor gene which encodes the protein neurofibromin. The diagnosis of NF 1 requires at least two of the following criteria: six or more café au lait macules on the skin which present as brownish smooth edged pigmentation and can be present at birth or during the first year of life, axillary or inguinal freckling, two or more neurofibromas of any type or one PN, two or more lisch nodules (brown spot on the iris), optic glioma, distinctive osseous bony dysplasia, (such as sphenoid wing dysplasia, or thinning of the long bone cortex) and involvement of a close family member with NF 1 by these criteria . Presence of oral lesions in NF 1 patients were found to be ranging from $4-7 \%$ upto almost $72 \%$ of cases but only a few cases of solitary involvement of oral mucosa have been described in literature. Typically radiologic manifestations include enlargement of mandibular foramen / canal, increased bone density, deep coronoid notch, concavity of medial surface of ramus as well as multiple radiolucencies.

However neurofibromatosis type 2 (NF2) also known as central neurofibromatosis ia an autosomal dominant disease which accounts for an extremely small percentage of total cases of NF. The hall mark of NF2 is the presence of bilateral vestibular schwanomas ${ }^{2}$.

Neurofibromas of the large nerves, which appear clinically as soft, drooping and doughy masses, are benign neoplasms composed of neuritis ,schwann cells, and fibroblasts with in a collagenous or myxoid matrix. In contrast to schwannomas, they are encapsulated and engulf the nerve of origin. Plexiform neurifibromas, forming tortuous cords along the segments and branches of a nerve with a tendency to grow centripedally, are poorly circumscribed tumors. This tumor is said to be indicative of VRD even though it may be the only clinical manifestation of the disease. Neurofibromas, associated with VRD, are generally encountered as multiple lesions, and rarely occurs as solitary finding as in our case ${ }^{2}$.

Tongue is the most commonly involved site following buccal mucosa, floor of the mouth, palate, lips and gingival ${ }^{5}$. The base of tongue is a relatively rare location and if involved may lead to upper airway obstruction ${ }^{6}$.

The treatment of such lesions is generally surgical excision and the diagnosis can only be confirmed and differentiated from schwannoma after histopathological examination as neurofibromatosis associated with VRD has greater potential for malignant transformation which has been reported to be about $5-16 \%{ }^{2}$. 
Neurofibromas are immunopositive for S-100 protein in $85-100 \%$ cases indicating its neural $\operatorname{origin}^{10}$. So, Immunohistochemistry with S-100 should be the confirmatory test of choice.

Neurofibromas have extensive vascularity and tend to bleed during surgery which should be kept in mind while attempting surgical excision. In our patient, despite of poor cleavage plane, we were able to accomplish complete extirpation of the lesion preserving the surrounding tongue tissue with minimum bleeding and Primary closure was done with 4-0 vicryl suture material . Patient was under regular follow up for six months, without any signs of recurrence fortunately.

\section{Conclusion}

Early diagnosis and treatment in such patients is very important along with regular follow up during their life time to detect recurrences or appearance of any other manifestations of VRD especially central nervous system tumors like acoustic schwannomas and optic nerve gliomas ${ }^{7}$.

\section{Conflict of Interest: Nil \\ Acknowledgement: Nil \\ Source of support: Nil}

\section{References}

1. Tetsuo S, Takao K, Disuke N, Takahiro K, Norio H, Fumio I,Solitary Neurofibroma of the oral mucosa : A previously undescribed variant of neurofibroma : Journal of oral science: $2002 ; 44 ; 59-63$.

2. Enis $A \mathrm{G}$ et al, Plexiform neurofibroma of tongue: a case report of a child ; The Turkish Journal of Pediatrics 2006;48;155158.

3. Luciana S M, Denise T O, Michele CP, Cleverson TS, Raul NF, Sporadic and multiple neurofibromas in the head and neck region : a retrospective study of 33 years, Clin. Oral Invest;2007;11: 165-169.
4. Aline CBRJ etal, Extraosseous solitary hard palate neurofibroma, Rev Bras Otorrinolaringol, 2008;74 (2);317.

5. Lahoz Zamarro MT, Galve Royo A. Neurofibroma of the tongue. An Otorrinolaringol Ibero Am 1990;17: 287295.

6. Crozier WC. Upper airway obstruction in neurofibromatosis. Anaesthesia 1987;42: 1209-1211

7. Pardos MD, Neoplasms of the nervous System In: Holland JF, Frei M (eds). Cancer Medicine ( $5^{\text {th }}$ Edition).London: B.C.Decker Inc;2000: 1055-1082.

8. Gallesio C, Berrone S. Schwannoma located in the tongue. A clinical case report.Minerva Stomatol 1992;41:583-590.

9. Benign tumors of peripheral nerves. In: Weiss SW, Goldblum JR (eds).Enzinger and Weiss's Soft Tissue Tumors (4th ed.).St Louis: Mosby Inc;2001:1111-1207.

10. Johnson MD, Glick AD, Davis BW. Immunohistochemical evaluation of Leu7,myelin basic-protein,S100-protein,glialfibrillary acidic protein, and LN3 immunoreactivity in nerve sheath tumors and sarcomas. Arch Pathol Lab Med 1988:112(2):155-160. 